\title{
Current practice of percutaneous coronary intervention on patients with acute coronary syndrome in Iran: A prospective observational study
}

\author{
Seyed Hashem Sezavar ${ }^{1}$, Morteza Hassanzadeh*2D, Davood Akhlagh Moayed ${ }^{3}$, Mahmood Tabandeh $^{4}$, \\ Massoud Ghasemi ${ }^{5}$, Seifollah Abdi ${ }^{6}$, Iraj Firoozi ${ }^{7}$, Pejman Golbidi ${ }^{8}$, Marzieh Pourjafari ${ }^{8}$, Negin Taslimi ${ }^{9}$, \\ Ali Asghar Akhlaghi ${ }^{10}$, Mahmoud Hashemian ${ }^{7}$
}

Received: 27 Sep 2019

Published: 27 Feb 2020

\begin{abstract}
Background: Frequent Percutaneous Coronary Intervention (PCI) procedures are being performed on a daily basis in Iran. However, no study has been reported on the current PCI practice in patients with acute coronary syndrome (ACS) in Iran. We aimed to describe the clinical characteristics and treatment patterns in Iranian ACS patients treated with PCI.

Methods: Between February 2017 and July 2017, ACS patients presented to 5 referral hospitals in two major cities of Iran (Tehran and Shiraz) were included in this observational study if aged $>18$ years and underwent PCI for ACS during hospitalization; and their clinical and procedural characteristics were collected. All data were entered into SPSS v.21 and descriptive statistics were performed.

Results: Of a total of 314 patients, 228 (73\%) were males, $162(52 \%)$ were diagnosed with ST-elevation myocardial infarction and $152(48 \%)$ with Unstable angina/ Non-ST elevation myocardial infarction. Trans-femoral approach was more often (64\%) used for PCI procedures. Stent placement was the most frequent (98\%) treatment strategy on PCI, with drug-eluting stent selected in the majority of subjects (98\%). The overall rate of PCI success was 95\%, with $4.1 \%$ PCI-related complications, and $1.6 \%$ post-PCI bleeding events. The vast majority of the study patients $(99 \%)$ were discharged with dual anti-platelet therapy.

Conclusion: In this study, we observed a high level of adherence to the currently accepted guidelines in the current PCI practice on ACS patients in Iran. Also we found our practice is highly in line with the global reduction trend in the PCI-related complications.
\end{abstract}

Keywords: Percutaneous coronary intervention, Acute coronary syndrome, Iran

Conflicts of Interest: Pejman Golbidi and Marzieh Pourjafari are Sanofi employees. None declared for other authors.

Funding: Sanofi-Aventis Group Iran Affiliate

*This work has been published under CC BY-NC-SA 1.0 license.

Copyright $@$ Iran University of Medical Sciences

Cite this article as: Sezavar SH, Hassanzadeh M, Akhlagh Moayed D, Tabandeh M, Ghasemi M, Abdi S, Firoozi I, Golbidi P, Pourjafari M, Taslimi $\mathrm{N}$, Akhlaghi AA, Hashemian M. Current practice of percutaneous coronary intervention on patients with acute coronary syndrome in Iran: A prospective observational study. Med J Islam Repub Iran. 2020 (27 Feb);34:13. https://doi.org/10.47176/mjiri.34.13

\section{Introduction}

Cardiovascular diseases (CVD) are the leading cause of death worldwide (1). Ischemic heart disease, including acute coronary syndrome (ACS), accounts for nearly half of the CVD-related mortalities (2). Despite significant developments in the management of patients with unstable

Corresponding author: Dr Morteza Hassanzadeh, hassanzadeh.m@iums.ac.ir

1. Research Center for Prevention of Cardiovascular Disease, Institute of Endocrinology \& Metabolism, Iran University of Medical Sciences, Tehran, Iran

2. Department of Internal Medicine, Rasoul-e-Akram Hospital, Iran University of Medical Sciences, Tehran, Iran

3. Cardiovascular Department, Pars General Hospital, Tehran, Iran

4. Kowsar Heart Hospital, Shiraz, Iran

5. Department of Cardiology, Imam Khomeini Medical Center, Tehran University of Medical Sciences, Tehran, Iran

6. Shahid Rajaei Heart Center, Tehran, Iran

7. Day hospital, Tehran, Iran

8. Sanofi-Aventis Group, Tehran, Iran

9. Iran university of Medical Sciences, Tehran, Iran

10. Department of Epidemiology and Reproductive Health, Reproductive Epidemiology Research Center, Royan Institute for Reproductive Biomedicine, ACECR, Tehran, Iran angina (UA), non-ST elevation myocardial infarction (NSTEMI) and ST-elevation myocardial infarction (STEMI), ACS remains a major global healthcare problem. In this context, Middle East countries are among the most concerning regions throughout the world; because of $\uparrow$ What is "already known” in this topic:

The current practice of Iranian physicians for in-hospital "medical management" of patients with acute coronary syndrome (ACS) has already been known.

\section{$\rightarrow$ What this article adds:}

The present study is the first to describe the current practice of "percutaneous coronary intervention" on patients with ACS in Iran. 
the overall younger average age of deaths due to CVD which represents greater national and financial burdens (3).

Among different modalities for managing ACS patients, percutaneous coronary intervention (PCI) has undergone tremendous growth in recent years. Along with developments in clinical approach and pharmacology, more complex ACS cases are now successfully treated with PCI that substantially improves their clinical outcomes (4). For a better implementation of evidence-based PCI recommendations into clinical practice, commitment to guidelines of well-regarded authorities has been strongly emphasized (5-8). Although several large registries have evaluated PCI practice in developed societies (9-11), little is known about PCI in developing countries. In addition, it has been noted that there are wide variations in ACS management and PCI utilization among different countries $(12,13)$. Therefore, local registries are needed for developing countries in order to find possible gaps between their actual clinical practice and international guidelines.

Numerous ACS patients undergo PCI on a daily basis in different cities of Iran. However, very limited nationwide data regarding the current PCI practice in Iran is available. Hence, the purpose of this investigation was to gain insights into the clinical characteristics, treatment patterns (adherence to guidelines) and in-hospital outcome in Iranian ACS patients treated with PCI.

\section{Methods \\ Study Participants}

Between February 2017 and July 2017, study subjects were prospectively recruited from ACS patients consecutively presented to the 5 referral hospitals in two major cities of Iran (Tehran, the capital of the country; and Shiraz, the main referral city in the south of Iran), among which 2 hospitals were in the 24/7 dedicated primary PCI centers. The patients were included if confirmedly diagnosed with ACS (STEMI, NSTEMI, or UA), and underwent PCI for ACS during the hospitalization, and signed informed consent. Considering the proposed rate of procedural success as about $72 \%$ [based on the information in a referenced Iranian study (14)], for finding a difference of 0.05 , we needed to enroll 323 cases. The sample size distribution among the study sites was based on the number of the patients and number of beds in each hospital. Seven independent physicians were asked to recruit patients from the study centers. Each physician consecutively recruited patients until the targeted number of patient in his/her center was reached.

\section{Study Protocol}

Study protocol was prepared in detail with eligibility criteria, logistics, and exact definition of all items. It was then reviewed and approved by all investigators from each collaborating site before the study was started. A detailed paper Case Report Form (CRF) was developed for recording data from recruited patients which included data on demographics, presenting symptom, medical history (CVD risk factors, etc.), First Medical Contact (FMC) time, FMC-to-PCI time, subtype of ACS, prescribed med- ications, procedural details on PCI, and PCI-related complications (if any). The data was collected and filled in the paper CRF by the responsible physician in each center.

Successful PCI was defined as post-PCI flow restoration with $<10 \%$ residual stenosis and no early stent thrombosis, nor emergent need for coronary artery bypass graft $(\mathrm{CABG})$ surgery (8). Based on some well-accepted guidelines, other items were defined as follows:

- ACS (5): A suspected coronary event that is subcategorized as STEMI, NSTEMI, or UA.

- STEMI (6): Presence of positive cardiac biomarkers and presumably new left bundle branch block or presumably new ischemic ST elevation of $>1 \mathrm{~mm}$ in two adjacent leads (except V2, V3 for which $>2 \mathrm{~mm}$ [men] or $>1.5 \mathrm{~mm}$ [women] are considered).

- NSTEMI (5): Presence of positive cardiac biomarkers without other STEMI criteria

- UA (5): Presence of ischemic chest discomfort (angina or its equivalents) with negative cardiac biomarkers and no ST elevation as previously described for STEMI.

- FMC time (6): The time point at which the STEMI patient was seen by medical personnel. For those patients who arrived at the first facility by emergency medical service (EMS), the time of EMS arrival to the patient was considered as FMC. For those with self- or familytransport, the time of arrival to the first facility was considered as FMC.

- FMC-to-PCI time (6): The time from FMC to the time of the beginning of PCI (i.e., wire insertion).

- PCI-related Complication (8): Occurrence of one of the followings during or after PCI (when not considered as a complication of the ACS itself): stent thrombosis (reinfarction), cardiogenic shock, new atrial fibrillation, ventricular tachycardia, ventricular fibrillation or cardiac arrest, suspected bleeding event (any bleeding diagnosed by the operating interventional cardiologist [at access site, retroperitoneal, gastrointestinal, genitourinary, etc.], whether it needs surgical/endoscopic intervention, packed cell transfusion or not), stroke, mechanical ventilatory support, emergency CABG, or PCI-related death.

\section{Statistical analysis}

All of the study data were entered into SPSS for Windows version 21.0. Descriptive statistics were performed, and results were expressed as frequency and percent, mean with standard deviation (SD), or median with interquartile range (IQR) where applicable. Some clinical subgroups of special interest were identified and baseline, angiographic and procedural characteristics and complications were compared between those subgroups. For continuous data, differences were calculated using the Student's t-test (or Mann-Whitney U test, Chi-square test, and Fisher's exact test); and for proportions, the Chisquare test and correlation coefficient were used. All statistical tests were two-tailed with a 0.05 significance level.

\section{Results}

\section{Baseline Characteristics}

During the 5-month course of this study, 317 patients were recruited. After excluding 3 cases with incomplete 


\begin{tabular}{|c|c|c|c|c|}
\hline Variable $^{*}$ & All $(\mathrm{N}=314)$ & STEMI $(\mathrm{N}=162)$ & UA/NSTEMI $(\mathrm{N}=152)$ & $P$ \\
\hline Age: mean (SD) & $62(12)$ & $61(12)$ & $63(11)$ & 0.380 \\
\hline Male gender & $228(73)$ & $121(75)$ & $107(70)$ & 0.394 \\
\hline Body weight: mean (SD) & 77 (12) & $76(11)$ & $78(14)$ & 0.399 \\
\hline Body mass index: mean (SD) & $26.9(4.0)$ & $26.8(3.9)$ & $27.2(4.3)$ & 0.411 \\
\hline Living area & & & & 0.044 \\
\hline Urban & $293(93)$ & $156(96)$ & $137(90)$ & \\
\hline Rural & $21(7)$ & $6(4)$ & $15(10)$ & \\
\hline Education Level & & & & 0.001 \\
\hline Illiterate & $40(13)$ & $25(15)$ & $15(10)$ & \\
\hline Primary & $77(25)$ & $50(31)$ & $27(18)$ & \\
\hline Secondary & $105(33)$ & $54(33)$ & $51(34)$ & \\
\hline University/Higher & $92(29)$ & $33(21)$ & $59(39)$ & \\
\hline \multicolumn{5}{|l|}{ Background/Risk Factors } \\
\hline Hypertension & $183(58)$ & $106(65)$ & $77(51)$ & $<0.001$ \\
\hline Hypercholesterolemia & $150(48)$ & $63(39)$ & $87(57)$ & 0.001 \\
\hline Diabetes mellitus & $73(23)$ & $32(20)$ & $41(27)$ & 0.130 \\
\hline Current smoker & $46(15)$ & $25(15)$ & $20(13)$ & 0.566 \\
\hline Chronic kidney disease & $17(5)$ & $8(5)$ & $9(6)$ & 0.701 \\
\hline Cerebrovascular disease & $7(2)$ & $2(1)$ & $5(3)$ & 0.270 \\
\hline Peripheral arterial disease & $4(1)$ & $2(1)$ & $2(1)$ & 1.000 \\
\hline Prior myocardial infarction & $32(10)$ & $10(6)$ & $22(14)$ & 0.013 \\
\hline Prior heart failure & $13(4)$ & $11(7)$ & $2(1)$ & 0.015 \\
\hline Prior PCI & $56(18)$ & $12(7)$ & $44(29)$ & $<0.001$ \\
\hline Prior CABG & $35(11)$ & $7(4)$ & $28(18)$ & $<0.001$ \\
\hline Prosthetic heart valve & $2(1)$ & $1(0.6)$ & $1(0.7)$ & 1.000 \\
\hline Atrial fibrillation/flutter & $5(2)$ & $1(0.6)$ & $4(3)$ & 0.202 \\
\hline
\end{tabular}

*Values are No. (\%) except otherwise specified; STEMI: ST Elevation MI; UA/NSTEMI: Unstable Angina/Non-ST Elevation MI; SD: Standard Deviation; PCI: Percutaneous Coronary Intervention; CABG: Coronary Artery Bypass Graft

CRF, a total of 314 patients were analyzed with a mean (SD) age of 62 (12) years. The majority of participants $(73 \%)$ were males and from urban areas (93\%). Other baseline characteristics are summarized in Table 1. As seen, the most frequent CVD risk factor was hypertension $(58 \%)$ followed by dyslipidemia $(48 \%)$ and diabetes mellitus (23\%). In addition, 91 subjects $(29 \%)$ had prior coronary revascularization, either PCI $(18 \%)$ or $\mathrm{CABG}$ $(11 \%)$.

\section{Clinical and Procedural Characteristics}

ACS patients in this study included 162 (52\%) STEMI and $152(48 \%)$ UA/NSTEMI patients (Table 2). Among STEMI subjects, the FMC-to-PCI time ranged from 15 to

\begin{tabular}{|c|c|c|c|c|}
\hline Variable $^{*}$ & All $(\mathrm{N}=314)$ & STEMI $(\mathrm{N}=162)$ & UA/NSTEMI $(\mathrm{N}=152)$ & $\mathrm{P}$ \\
\hline \multicolumn{5}{|l|}{ Vital signs at presentation $^{* *}$} \\
\hline Systolic blood pressure & $133(20)$ & $131(20)$ & $135(19)$ & 0.041 \\
\hline Diastolic blood pressure & $79(11)$ & $79(11)$ & $79(11)$ & 0.709 \\
\hline Heart rate & $76(11)$ & $79(12)$ & $74(10)$ & $<0.001$ \\
\hline Chest pain at presentation & $296(94)$ & $158(98)$ & $138(91)$ & 0.006 \\
\hline \multicolumn{5}{|l|}{ Transportation mean } \\
\hline By EMS & - & $92(57)$ & - & - \\
\hline By Family/Self & - & $52(32)$ & - & - \\
\hline Unknown & - & $18(11)$ & - & - \\
\hline FMC-to-PCI time (minutes) ${ }^{* * *}$ & - & $65(45-110)$ & - & - \\
\hline PCI approach site & & & & 0.222 \\
\hline Femoral artery & $199(64)$ & $110(68)$ & $89(58)$ & \\
\hline Radial artery & $110(35)$ & $50(31)$ & $60(39)$ & \\
\hline Brachial artery & $5(1)$ & $2(1)$ & $3(2)$ & \\
\hline PCI indication & & & & NA \\
\hline Primary PCI for STEMI & $149(47)$ & $149(92)$ & NA & \\
\hline Rescue PCI for STEMI & $9(3)$ & $9(6)$ & NA & \\
\hline PCI after successful thrombolysis for STEMI & $4(1)$ & $4(2)$ & NA & \\
\hline PCI for UA/NSTEMI & $152(48)$ & NA & $152(100)$ & \\
\hline Disease extent & & & & 0.493 \\
\hline 1 vessel disease & $109(35)$ & $52(32)$ & $57(38)$ & \\
\hline 2 vessel disease & $105(33)$ & $58(36)$ & $47(31)$ & \\
\hline 3 vessel disease & $100(32)$ & $52(32)$ & $48(31)$ & \\
\hline \multicolumn{5}{|l|}{ Lesion location } \\
\hline LAD & $175(56)$ & $105(65)$ & $70(46)$ & 0.001 \\
\hline RCA & $134(42)$ & $82(51)$ & $52(34)$ & 0.003 \\
\hline LCX & 77 (24) & $48(30)$ & 29 (19) & 0.030 \\
\hline OM & 39 (12) & 29 (18) & $10(7)$ & 0.002 \\
\hline Diagonal & $25(8)$ & $13(8)$ & $12(8)$ & 0.966 \\
\hline Left main & $8(3)$ & $5(3)$ & $3(2)$ & 0.532 \\
\hline
\end{tabular}




\begin{tabular}{|c|c|c|c|c|c|c|}
\hline \multicolumn{7}{|l|}{ Table 2. Ctd } \\
\hline \multicolumn{2}{|l|}{ Variable $^{*}$} & All $(\mathrm{N}=314)$ & STEMI $(\mathrm{N}=162)$ & \multicolumn{2}{|c|}{ UA/NSTEMI $(\mathrm{N}=152)$} & $\mathrm{P}$ \\
\hline \multicolumn{7}{|l|}{ Treatment strategy } \\
\hline \multicolumn{2}{|l|}{ Stent placement } & $308(98)$ & $159(98)$ & & (98) & 0.936 \\
\hline \multicolumn{2}{|l|}{ Pre-dilatation } & $211(68)$ & $144(89)$ & & 44) & $<0.001$ \\
\hline \multicolumn{2}{|l|}{ Post-dilatation } & $258(82)$ & $142(88)$ & & (76) & 0.009 \\
\hline \multicolumn{2}{|l|}{ Thrombus aspiration } & $25(8)$ & $21(13)$ & & & 0.001 \\
\hline \multicolumn{2}{|l|}{ Stent type } & & & & & 0.956 \\
\hline \multicolumn{2}{|l|}{ Drug-eluting stent } & $309(98)$ & $161(99)$ & & (97) & \\
\hline \multicolumn{2}{|l|}{ Bare-metal stent } & $2(1)$ & $1(1)$ & & & \\
\hline \multicolumn{2}{|l|}{ Successful PCI } & $298(95)$ & $148(91)$ & & (99) & 0.479 \\
\hline \multicolumn{7}{|c|}{$\begin{array}{l}\text { *Values are No. (\%) except otherwise specified; **Values are mean (standard deviation); ***Value is median (interquartile range); STEMI: ST Elevation M } \\
\text { UA/NSTEMI: Unstable Angina/Non-ST Elevation MI; EMS: Emergency Medical Service; FMC: First Medical Contact; PCI: Percutaneous Coronary Interventior } \\
\text { LAD: Left Anterior Descending artery; RCA: Right Coronary Artery; LCX: Left Circumflex artery; OM: Obtuse Marginal artery. }\end{array}$} \\
\hline \multicolumn{7}{|c|}{ Table 3. First medical contact (FMC)-to-PCI time for STEMI patients between subgroups } \\
\hline FMC-to-PCI time (minutes) & $\mathrm{N}(\%)$ & Mean & Median (IQR) & Min & Max & $\mathrm{P}$ \\
\hline & Transportation mean & & & & $<0.001$ \\
\hline By Self/Family & $52(36)$ & 258 & $130(60-250)$ & 30 & 1580 & \\
\hline \multicolumn{2}{|l|}{ By EMS } & 85 & $60(40-80)$ & 18 & 1185 & \\
\hline \multicolumn{2}{|l|}{ Gender } & & & & & 0.525 \\
\hline Male & $107(74)$ & 140 & $65(45-110)$ & 15 & 1545 & \\
\hline Female & $37(26)$ & 173 & $65(50-120)$ & 19 & 1580 & \\
\hline Education & & & & & & 0.073 \\
\hline Illiterate & $22(15)$ & 168 & $66(50-96)$ & 26 & 1580 & \\
\hline Primary & $44(31)$ & 110 & $65(48-115)$ & 15 & 1176 & \\
\hline Secondary & $49(34)$ & 131 & $60(45-110)$ & 18 & 1185 & \\
\hline University / Higher & $29(20)$ & 223 & $65(40-115)$ & 18 & 1545 & \\
\hline
\end{tabular}

PCI: Percutaneous Coronary Intervention; STEMI: ST Elevation MI; IQR: Inter-Quartile Range; EMS: Emergency Medical Service

1580 minutes (min), with mean and median (IQR) of 149 and 65 (45-110) min, respectively. There was a statistically significant difference in FMC-to-PCI time between EMS transported STEMI patients and self/familytransported ones (median [IQR]: 60 [40-80] min vs. 130 [60-250] min, respectively; $\mathrm{P}<0.001)$. No difference, however, was found in terms of gender, living area, or education level (Table 3).

Details on clinical features and procedural techniques of the study participants are seen in Table 2. Around twothird of procedures $(64 \%)$ were performed via femoral artery access. Nearly two-thirds of patients $(65 \%)$ had multivessel disease, whereas $35 \%$ had single-vessel involvement. The most frequently involved vessel was the left anterior descending artery $(56 \%)$, followed by the right coronary artery $(42 \%)$ and the left circumflex artery $(24 \%)$.

The overall PCI success rate was $95 \%$. Stent placement was performed in $98 \%$ of the total study subjects. Drugeluting stent (DES) was placed in $98 \%$ of patients; balloon angioplasty without stent implementation was performed in $1 \%$, and bare-metal stent (BMS) was placed in only $1 \%$ of patients.

\section{Medications and Complications}

Table 4 shows the prescribed medications to the study patients. COX inhibitor, P2Y12 inhibitor, and dual antiplatelet therapy (DAPT) were given to the most of the study subjects both at the emergency department (ED) $(87 \%, 89 \%$, and $87 \%$ respectively) and at discharge (98\%, $99.7 \%$, and $99 \%$ respectively). Glycoprotein IIb/IIIa inhibitors were used for near to one quarter $(24 \%)$ of the total cases. Whereas the vast majority $(99 \%)$ of patients received anticoagulation in hospital, only $2 \%$ were discharged with a vitamin $\mathrm{K}$ antagonist.

The overall rate of PCI-related complications was $4.1 \%$, most of which $(1.6 \%)$ related to the suspected bleeding events. No PCI-related mortality was reported in this study population (Table 5).

Table 4. Medications during hospitalization and at discharge

\begin{tabular}{|c|c|c|c|c|}
\hline Variable $^{*}$ & All $(\mathrm{N}=314)$ & STEMI $(\mathrm{N}=162)$ & UA/NSTEMI (N=152) & $\mathrm{P}$ \\
\hline \multicolumn{5}{|l|}{ Drugs prescribed at ED/Cath lab } \\
\hline COX inhibitor & $274(87)$ & $160(99)$ & $114(75)$ & $<0.001$ \\
\hline P2Y12 inhibitor & $280(89)$ & $160(99)$ & $120(79)$ & $<0.001$ \\
\hline DAPT & $273(87)$ & $158(98)$ & $113(74)$ & $<0.001$ \\
\hline Anticoagulant & $312(99)$ & $162(100)$ & $150(99)$ & 0.143 \\
\hline Vitamin $\mathrm{K}$ antagonist & $0(0)$ & $0(0)$ & $0(0)$ & 1.000 \\
\hline Glycoprotein IIb/IIIa inhibitor & $76(24)$ & $66(41)$ & $10(7)$ & $<0.001$ \\
\hline \multicolumn{5}{|l|}{ Drugs prescribed at discharge } \\
\hline COX inhibitor & $309(98)$ & $160(99)$ & $149(98)$ & 0.601 \\
\hline P2Y12 inhibitor & $313(99.7)$ & $161(99)$ & $152(100)$ & 0.332 \\
\hline DAPT & $311(99)$ & $159(98)$ & $149(98)$ & 0.938 \\
\hline Vitamin $\mathrm{K}$ antagonist & $6(2)$ & $2(1)$ & $4(3)$ & 0.366 \\
\hline
\end{tabular}


Table 5. PCI-related complications in study participants

\begin{tabular}{lc}
\hline Complication & Frequency $(\%)$ \\
\hline Stent thrombosis (re-infarction) & $2(0.6)$ \\
Cardiogenic Shock & $1(0.3)$ \\
New Atrial Fibrillation & $2(0.6)$ \\
Ventricular Tachycardia & $2(0.6)$ \\
Ventricular Fibrillation / Cardiac Arrest & $1(0.3)$ \\
Suspected Bleeding Event & $5(1.6)$ \\
Stroke & $0(0.0)$ \\
Mechanical Ventilatory Support & $0(0.0)$ \\
Emergency CABG & $0(0.0)$ \\
Death & $0(0.0)$ \\
Total & $13(4.1)$ \\
\hline PCI: Percutaneous Coronary Intervention; CABG: Coronary Artery Bypass Graft
\end{tabular}

PCI: Percutaneous Coronary Intervention; CABG: Coronary Artery Bypass Graft

\section{Discussion}

To the best knowledge of the authors, no specific registry for PCI practice has yet been performed by the countries in our region. Moreover, this is the first nationwide study in Iran that specifically focused on the characteristics of the current PCI practice in ACS patients. Our main results included a $52 \%$ rate of STEMI among ACS patients, a median (IQR) of 65 (45-110) min for FMC-toPCI time, a $98 \%$ rate for selecting DES for PCI, a $64 \%$ rate of trans-femoral approach for PCI, a PCI success rate of $95 \%$ with $4.1 \%$ PCI-related complications, and a $99 \%$ rate for DAPT at discharge.

Nearly one-half $(52 \%)$ of the ACS patients in the current study had STEMI, which is similar to the STEMI rates both reported in a study from Europe and Mediterranean basin (15) and many other studies from developing countries in our region (16-19). However, a significantly lower STEMI proportion was reported in a recent ACS registry from Iran, the IPACE2 (Iranian Project for Assessment of Coronary Events 2) Study (20). Although hypertension and male gender were more frequent in our study population compared to the IPACE2 Study (58\% vs. $50 \%$; and $73 \%$ vs. $65 \%$, respectively), the notable difference in STEMI rate could be best attributed to the different study populations. We included those ACS patients who underwent PCI during hospitalization, but the IPACE2 investigators included all hospitalized ACS patients, either underwent PCI or did not.

According to the guidelines from the American College of Cardiology/American Heart Association (ACC/AHA) (6) and the European Society of Cardiology (7), the "total ischemic time" is recommended not to exceed $120 \mathrm{~min}$ for STEMI patients. In this study, we found the median (IQR) of FMC-to-PCI time for STEMI patients is 65 (45-110) min which is an acceptable result overall. However, among STEMI patients, the FMC-to-PCI time for the subgroup of those with self- or family-transportation to ED (mean= $258 \mathrm{~min}$; median= $130 \mathrm{~min}$ ) was more than twice as late as those who transferred by EMS (mean $=85$ min; median= $60 \mathrm{~min}$ ). Considering our definition of FMC ("the time of EMS arrival to the patient" for EMStransported patients vs. "the time of arrival to the first facility" for those with self- or family-transportation), this finding supposes that, in real practice, when a given STEMI patient is presented to ED, the situation would be more seriously taken when he/she has been transferred by EMS than when transferred by his/her own family. This interesting issue could be targeted in future studies. Such issues as the method of transport among UA/NSTEMI patients and the onset of symptom-to-FMC time are also interesting for future investigations.

The rate of DES use in the current investigation was as high as $98 \%$. After being approved by the USA Food and Drug Administration (FDA), the use of DES was rapidly increased by up to $84 \%$ of all stents placed during 2004 2006 (21-23). In 2006, however, the advisory statement by the FDA on the risk of late stent thrombosis after DES transiently declined its use to 59\% during 2007-2008. Then again, the prevalence of DES use approximated $80 \%$ of all PCI procedures during 2012-2014, with an estimated annual increase over the recent years (21-23). When compared to BMS, the main advantage of DES is the lower rate of in-stent restenosis which is for the use of antiproliferative drug coatings. Although some concerns have been raised for DES about the risk of "very late" in-stent thrombosis among STEMI patients (24), data from recent literature supports the overall superiority of DES over BMS in terms of lower risk for target vessel MI and cardiac death as well as lower risk of in-stent thrombosis with DES than with BMS in STEMI cases (25). Nevertheless, when the risk of bleeding is a concern in a given patient, BMS might be selected over DES because it needs a shorter duration of DAPT after PCI. Practically, according to the current literature, when PCI is planned for a patient, DES should be selected as a routine choice of stent except when the patient cannot continue DAPT for at least 3 months after PCI (e.g., in case of planned noncardiac surgery) (26). Therefore, the extremely high rate of DES in Iranian PCI-capable centers in this study is seemingly in line with the current recommendations. However, it could raise the concern that the Iranian interventionists may overlook to consider the specific patients' characteristics (in terms of bleeding risk, planned surgery [if any], good or poor adherence to DAPT, etc.) before deciding for stent selection.

We found that the trans-femoral approach was more often $(64 \%)$ used for PCI procedures among Iranian interventionists. Although lower net adverse events (esp. bleeding) have been reported in the trans-radial PCI approach for ACS (27), those benefits have been more observed in the high-volume radial PCI hospitals ( $>80 \%$ of PCIs via radial artery access) (28). Also taking into consideration that the trans-radial approach makes more radiation exposure to the operator (29), it could be suggest- 
ed that for moderate to high-volume femoral PCI centers with low bleeding events, trying to change the practice to radial access might result in minimal marginal benefit. In this investigation with the rate of suspected bleeding events as low as $1.6 \%$, perhaps there is no need to insist on changing the practice from femoral to radial approach.

The rate of post-PCI bleeding events $(1.6 \%)$ and PCIrelated complications $(4.1 \%)$, as well as the overall procedural success rate of $95 \%$ in this study, are all similar to those rates reported by Western countries (30), and to some extent better than the results reported by some Eastern nations (31). It means that the real PCI practice in Iran is in line with the global reduction trend in the PCI-related complications (32).

Finally, the rate of DAPT at ED was acceptably high $(87 \%)$ in this registry, and the total proportion of those patients who discharged with dual anti-platelet agents was as high as $99 \%$ which is significantly higher than the values reported from the previous Iranian ACS registry (IPACE2) (20) and many other registries from developing countries (33-36). After a specific focus on the current practice of other countries in our region, the rate of DAPT is found from as low as $6 \%$ (40) to the rates around 45 to $68 \%(16,17)$, which proves our performance in DAPT for ACS patients as excellently higher. According to the literature, in spite of the ACC/AHA recommendations about the beneficial effects of DAPT for ACS patients $(5,6)$, underutilization of DAPT is a global trend (36-38). That trend has been reported to be more pronounced in those ACS patients who do not undergo PCI $(15,39)$; a fact that describes the observed rate difference in the use of DAPT in this study and the IPACE2 registry. After analyzing the subgroups separately, however, we found a significantly less proportion of the patients with UA/NSTEMI (74\%) than those with STEMI $(98 \%)$ received DAPT $(\mathrm{p}<0.001)$ in ED. A similar trend to less use of DAPT among UA/NSTEMI patients than STEMIs has also been reported in previous investigations $(15,16,36,38,39)$. Given the weight of evidence supporting the use of DAPT in all ACS patients, more reinforcement on the appropriate use of DAPT in ED for UA/NSTEMI patients seems necessary in retraining programs for physicians.

The main limitation of this study is the undeniable bias in the selection of our sample. Although this was a multicenter study, patients and centers participating in this registry may not have been well representative of all Iranian PCI procedures on ACS patients. Not only the small number of the recruited patients (most of whom from urban areas) limits the generalizability of the results, but also the selected PCI centers from 2 main referral provinces might not reflect the current PCI practice in the other regions of the country.

\section{Conclusion}

In this observational prospective multicenter study on PCI practice in ACS patients in Iran, the results demonstrated good adherence of the Iranian interventionists to the ACC/AHA guidelines.

\section{Acknowledgements}

The authors would like to acknowledge the SanofiAventis Group Iran Affiliate for their funding and technical support of the project.

\section{Conflict of Interests}

Pejman Golbidi and Marzieh Pourjafari are Sanofi employees. The Other authors declare that they have no competing interests.

\section{References}

1. World Health Organization. Fact sheet: Cardiovascular diseases (CVDs). 2017. Available at http://www.who.int/mediacen tre/factsheets/fs317/en/Accessed 10 December 2018.

2. Mendis S. Global progress in prevention of cardiovascular disease. Cardiovasc Diagn Ther. 2017 Apr; 7(Suppl 1):S32.

3. Moran AE, Forouzanfar MH, Roth GA, Mensah GA, Ezzati M, Murray $\mathrm{CJ}$, et al. Temporal trends in ischemic heart disease mortality in 21 world regions, 1980 to 2010: the Global Burden of Disease 2010 study. Circulation. 2014 Apr 8;129(14):1483-92.

4. Grech $\mathrm{ED}$. $\mathrm{ABC}$ of interventional cardiology: percutaneous coronary intervention. I: history and development. BMJ. 2003 May 17;326(7398): 1080 .

5. Amsterdam EA, Wenger NK, Brindis RG, Casey DE, Ganiats TG, Holmes DR, et al. 2014 AHA/ACC guideline for the management of patients with non-ST-elevation acute coronary syndromes: a report of the American College of Cardiology/American Heart Association Task Force on Practice Guidelines. J Am Coll Cardiol. 2014 Dec 23;64(24):e139-228.

6. O'gara PT, Kushner FG, Ascheim DD, Casey DE, Chung MK, De Lemos JA, et al. 2013 ACCF/AHA guideline for the management of ST-elevation myocardial infarction: executive summary: a report of the American College of Cardiology Foundation/American Heart Association Task Force on Practice Guidelines. J Am Coll Cardiol. 2013 Jan 29;61(4):485-510.

7. Ibanez B, James S, Agewall S, Antunes MJ, Bucciarelli-Ducci C, Bueno $\mathrm{H}$, et al. 2017 ESC Guidelines for the management of acute myocardial infarction in patients presenting with ST-segment elevation: The Task Force for the management of acute myocardial infarction in patients presenting with ST-segment elevation of the European Society of Cardiology (ESC). Eur Heart J. 2017 Aug 26;39(2):119-77.

8. Levine GN, Bates ER, Blankenship JC, Bailey SR, Bittl JA, Cercek $\mathrm{B}$, et al. $2015 \mathrm{ACC} / \mathrm{AHA} / \mathrm{SCAI}$ focused update on primary percutaneous coronary intervention for patients with ST-elevation myocardial infarction: an update of the $2011 \mathrm{ACCF} / \mathrm{AHA} / \mathrm{SCAI}$ guideline for percutaneous coronary intervention and the 2013 ACCF/AHA guideline for the management of ST-elevation myocardial infarction. J Am Coll Cardiol. 2016 Mar 15;67(10):1235-50.

9. Rao SV, Ou FS, Wang TY, Roe MT, Brindis R, Rumsfeld JS, et al. Trends in the prevalence and outcomes of radial and femoral approaches to percutaneous coronary intervention: a report from the National Cardiovascular Data Registry. JACC Cardiovasc Interv. 2008 Aug 1;1(4):379-86

10. Capodanno D, Gori T, Nef H, Latib A, Mehilli J, Lesiak M, et al. Percutaneous coronary intervention with everolimus-eluting bioresorbable vascular scaffolds in routine clinical practice: early and midterm outcomes from the European multicenter GHOST-EU registry. EuroIntervention. 2015 Feb 22;10(10):1144-53.

11. Galassi AR, Tomasello SD, Reifart N, Werner GS, Sianos G, Bonnier $\mathrm{H}$, et al. In-hospital outcomes of percutaneous coronary intervention in patients with chronic total occlusion: insights from the ERCTO (European Registry of Chronic Total Occlusion) registry. EuroIntervention. 2011 Aug;7(4):472-9.

12. Fox KA, Goodman SG, Klein W, Brieger D, Steg PG, Dabbous O, et al. Management of acute coronary syndromes. Variations in practice and outcome. Findings from the Global Registry of Acute Coronary Events (GRACE). Eur Heart J. 2002 Aug 1;23(15):1177-89.

13. Fox KA, Goodman SG, Anderson Jr FA, Granger CB, Moscucci M, Flather MD, et al. From guidelines to clinical practice: the impact of hospital and geographical characteristics on temporal trends in the management of acute coronary syndromes: the Global Registry of 
Acute Coronary Events (GRACE). Eur Heart J. 2003 Aug $1 ; 24(15): 1414-24$.

14. Khosravi AR, Hoseinabadi M, Pourmoghaddas M, Shirani S, Paydari N, Sadeghi M, et al. Primary percutaneous coronary intervention in the Isfahan province, Iran; A situation analysis and needs assessment. ARYA Atheroscler. 2013 Jan;9(1):38

15. Mandelzweig L, Battler A, Boyko V, Bueno H, Danchin N, Filippatos G, et al. The second Euro Heart Survey on acute coronary syndromes: characteristics, treatment, and outcome of patients with ACS in Europe and the Mediterranean Basin in 2004. Eur Heart J. 2006 Aug 14;27(19):2285-93.

16. AlHabib KF, Sulaiman K, Al-Motarreb A, Almahmeed W, Asaad N, Amin $\mathrm{H}$, et al. Baseline characteristics, management practices, and long-term outcomes of Middle Eastern patients in the Second Gulf Registry of Acute Coronary Events (Gulf RACE-2). Ann Saudi Med. 2012;32(1).

17. Yusufali AM, AlMahmeed W, Tabatabai S, Rao K, Binbrek A. Acute coronary syndrome registry from four large centres in United Arab Emirates (UAE-ACS Registry). Heart Asia. 2010 Jan 1;2(1):118-21.

18. Xavier D, Pais P, Devereaux PJ, Xie C, Prabhakaran D, Reddy KS, et al. Treatment and outcomes of acute coronary syndromes in India (CREATE): a prospective analysis of registry data. Lancet. $2008 \mathrm{Apr}$ 26;371(9622):1435-42.

19. AlHabib KF, Hersi A, AlFaleh H, AlNemer K, AlSaif S, Taraben A, et al. Baseline characteristics, management practices, and in-hospital outcomes of patients with acute coronary syndromes: results of the Saudi project for assessment of coronary events (SPACE) registry. J Saudi Heart Assoc. 2011 Oct 1;23(4):233-9.

20. Kassaian SE, Masoudkabir F, Sezavar H, Mohammadi M, Pourmoghaddas A, Kojouri J, et al. Clinical characteristics, management and 1-year outcomes of patients with acute coronary syndrome in Iran: the Iranian Project for Assessment of Coronary Events 2 (IPACE2). BMJ Open. 2015 Dec 1;5(12):e007786.

21. Go AS. On behalf of the American Heart Association Statistics Committee and Stroke Statistics Subcommittee. Heart disease and stroke statistics-2013 update: a report from the American Heart Association. Circulation. 2013;127:e6-245.

22. Alfonso F, Byrne RA, Rivero F, Kastrati A. Current treatment of instent restenosis. J Am Coll Cardiol. 2014 Jun 24;63(24):2659-73.

23. Rymer JA, Harrison RW, Dai D, Roe MT, Messenger JC, Anderson HV, et al. Trends in bare-metal stent use in the United States in patients aged $\geq 65$ years (from the CathPCI Registry). Am J Cardiol. 2016 Oct 1;118(7):959-66.

24. Sethi A, Bahekar A, Bhuriya R, Bajaj A, Kovacs D, Ahmed A, et al. Drug-eluting stents versus bare metal stents in ST elevation myocardial infarction at a follow-up of three years or longer: A meta-analysis of randomized trials. Exp Clin Cardiol. 2012;17(4):169.

25. Sabaté M, Räber L, Heg D, Brugaletta S, Kelbaek H, Cequier A, et al. Comparison of newer-generation drug-eluting with bare-metal stents in patients with acute ST-segment elevation myocardial infarction: a pooled analysis of the EXAMINATION (clinical Evaluation of the Xience-V stent in Acute Myocardial INfArcTION) and COMFORTABLE-AMI (Comparison of Biolimus Eluted From an Erodible Stent Coating With Bare Metal Stents in Acute ST-Elevation Myocardial Infarction) trials. JACC Cardiovasc Interv. 2014 Jan 1;7(1):55-63.

26. Colombo A, Giannini F, Briguori C. Should we still have bare-metal stents available in our catheterization laboratory? J Am Coll Cardiol. 2017 Jul 24;70(5):607-19.

27. Valgimigli M, Gagnor A, Calabró P, Frigoli E, Leonardi S, Zaro T, et al. Radial versus femoral access in patients with acute coronary syndromes undergoing invasive management: a randomized multicenter trial. Lancet. 2015 Jun 20;385(9986):2465-76.

28. Valgimigli M, Calabrò P, Cortese B, Frigoli E, Garducci S, Rubartelli P, et al. Scientific foundation and possible implications for practice of the Minimizing Adverse Hemorrhagic Events by Transradial Access Site and Systemic Implementation of AngioX (MATRIX) trial. J Cardiovasc Transl Res. 2014 Feb 1;7(1):101-11.

29. Sciahbasi A, Frigoli E, Sarandrea A, Rothenbühler M, Calabrò P, Lupi A, et al. Radiation exposure and vascular access in acute coronary syndromes: the RAD-Matrix trial. J Am Coll Cardiol. 2017 May 15;69(20):2530-7.

30. Anderson HV, Shaw RE, Brindis RG, Hewitt K, Krone RJ, Block $\mathrm{PC}$, et al. A contemporary overview of percutaneous coronary interventions: the American College of Cardiology-National Cardiovascu- lar Data Registry (ACC-NCDR). J Am Coll Cardiol. 2002 Apr 3;39(7):1096-103.

31. Jang JS, Han KR, Moon KW, Jeon DW, Shin DH, Kim JS, et al. The current status of percutaneous coronary intervention in Korea: based on year 2014 cohort of Korean Percutaneous Coronary Intervention (K-PCI) Registry. Korean Circ J. 2017 May 1;47(3):328-40.

32. Subherwal S, Peterson ED, Dai D, Thomas L, Messenger JC, Xian $\mathrm{Y}$, et al. Temporal trends in and factors associated with bleeding complications among patients undergoing percutaneous coronary intervention: a report from the National Cardiovascular Data CathPCI Registry. J Am Coll Cardiol. 2012 May 22;59(21):1861-9.

33. Karrowni W, Abdallah M, Itani S, Kobeissi L, Shamseddeen W, Dakik HA. Management of acute coronary syndromes in developing countries: are we complying with practice guidelines? Int J Cardiol. 2010 Sep 24;144(1):95-6.

34. Ahmad WA, Ramesh SV, Zambahari R. Malaysia-ACute CORonary syndromes Descriptive study (ACCORD): evaluation of compliance with existing guidelines in patients with acute coronary syndrome. Singapore Med J. 2011 Jul 1;52(7):508-11.

35. Cheng CI, Chen CP, Kuan PL, Lei MH, Liau CS, Ueng KC, et al. The Causes and Outcomes of Inadequate Implementation of Existing Guidelines for Antiplatelet Treatment in Patients with Acute Coronary Syndrome: The Experience from Taiwan Acute Coronary Syndrome Descriptive Registry (T-ACCORD Registry). Clin Cardiol. 2010 Jun;33(6):E40-8.

36. Poloński L, Gąsior M, Gierlotka M, Kalarus Z, Cieśliński A, Dubiel JS, et al. Original article Polish Registry of Acute Coronary Syndromes (PL-ACS) Characteristics, treatments and outcomes of patients with acute coronary syndromes in Poland. Kardiol Pol. 2007;65(8):861-72.

37. Gibson CM. NRMI and current treatment patterns for ST-elevation myocardial infarction. Am Heart J. 2004 Nov 1;148(5):S29-33.

38. Xavier D, Pais P, Devereaux PJ, Xie C, Prabhakaran D, Reddy KS, et al. Treatment and outcomes of acute coronary syndromes in India (CREATE): a prospective analysis of registry data. Lancet. $2008 \mathrm{Apr}$ 26:371(9622):1435-42.

39. ACCESS Investigators. Management of acute coronary syndromes in developing countries: acute coronary events-a multinational survey of current management strategies. Am Heart J. 2011;162:852-9.e22.

40. Zubaid M, Rashed WA, Saad H, Attiya A, Al-Banat BA, Ridha M, et al. Kuwait acute coronary syndromes registry: baseline characteristics, management practices and in-hospital outcomes of patients hospitalized with acute coronary syndromes in Kuwait. Med Princ Pract. 2007;16(6):407-12. 